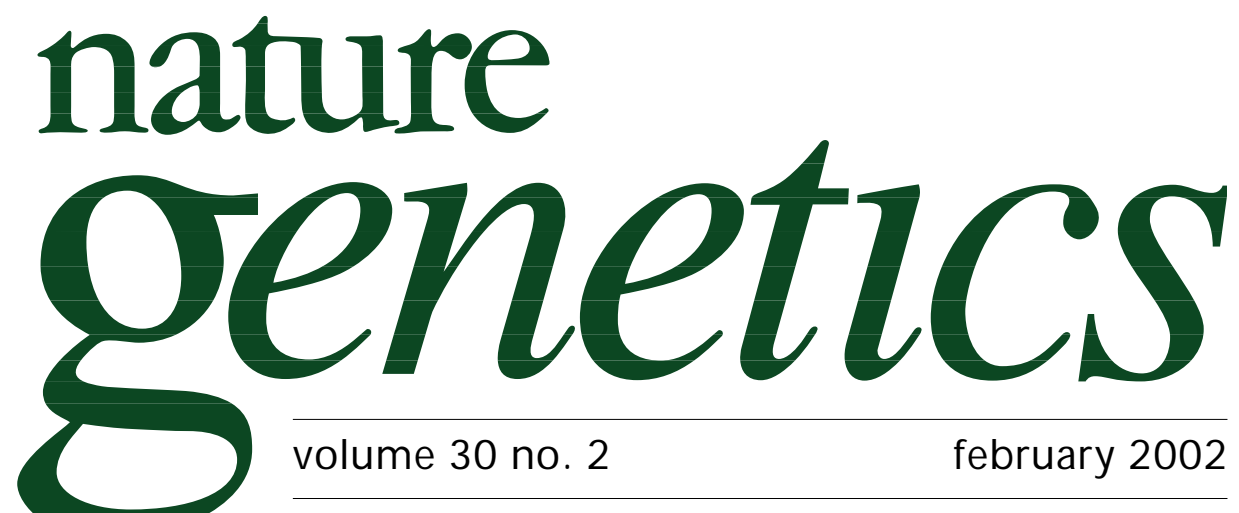

\title{
The HGP: end of phase 1
}

Come April 2003 or thereabouts, when an international public consortium plans to wrap up its large-scale gathering of human genome sequence data, the Human Genome Project will be over. "We'll have the sequence," as the University of Washington's Maynard Olson dryly observed at a recent gathering of project researchers in Airlie, Virginia. "That's something we all agree on-even though it's not true."

But the dotting of the i's and crossing of the t's that will remain after then does not a global project make. In a straw poll at the same meeting, most of the researchers backed a suggestion that the Human Genome Project should declare victory at that stage, and that their combined efforts should continue under some new designation.

So what comes next? Scientifically, the various areas of potential follow-up to the project are obvious: from a researcher's point of view, there is plenty of work to be done. Institutionally, however, the question is less of a slam-dunk. Genome sequencing operations at the US Department of Energy, where the project started, the Wellcome Trust's Sanger Centre, and the Whitehead Institute at the Massachusetts Institute of Technology, each face difficult choices at this time. But nowhere is the issue of follow-through more pressing than at the National Human Genome Research Institute (NHGRI), the rapidly-expanding branch of the National Institutes of Health whose entire history has been inextricably linked to the human genome project.

The NHGRI is drawing up a new, strategic plan to take effect from April 2003, and the meeting at Airlie was the first step in sketching out this plan. One thing the meeting agreed on was the danger of putting too much stock in other megaprojects-such as the sequencing of additional genomes. In his meeting summary, Olson likened biologists' dread of such an approach to the US Air Force's sensible aversion to ordering large numbers of inflexible, expensive B2 bombers.

Rather than supporting such projects, the real challenge for the NHGRI is to build bridges between its grantees and therapeutics. Notwithstanding biologists' deep desire to understand the genome, their most immediate challenge is to make it relevant to public health. This relevance will not be found by identifying genes associated with rare hereditary diseases, but by working with specialists who understand drug development to tackle common, complex diseases. The NHGRI needs to embark on this path without treading on the toes of other major NIH institutes. This won't be easy. It has little over a year to figure out a coherent strategy that will convince the public and the Congress that the institute has a central role in NIH's public health mission.

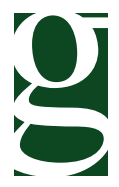

